\title{
LA REFORMA DEL ESTADO EN 2007 Y 2008
}

\section{Jorge CARPIZO*}

RESUMEN: Con la noción de flexibilidad en la reforma de la Constitución mexicana, construida desde 1988 desde el diálogo y la negociación políticas de coaliciones necesarias, el autor hace un recuento de las reformas constitucionales empezando por la política de 1977 , seguida de las que se produjeron desde entonces y hasta 2001, y las del sexenio de 2000 a 2006, para hacer finalmente una referencia específica a las de 2007, haciendo especial énfasis en el proceso de reforma del Estado llevado a cabo de 2000 a 2007. Una parte importante del artículo está constituida por reflexiones sobre la reforma judicial de junio de 2008 y sobre el régimen de Estado y de gobierno. La experiencia obtenida durante las últimas décadas de diálogo y negociación políticas, concluye el autor, resulta necesaria para que las reformas a la Constitución continúen realizándose en paz.

Palabras clave: reforma constitucional, reforma del Estado, reforma judicial, regímenes de gobierno y de Estado.
ABSTRACT: Through the notion of plasticity in the reform of the Mexican Constitution, that started in 1988 as a result of the dialogue and political negotiation of necessary coalitions, the author summarizes the constitutional reforms beginning with the political reform of 1977, followed by the reforms that took place since then and until 2001, as well as those of the presidential term 2000-2006, and ends by specifically referring to the reforms of 2007, where the process of State reform during 2000 to 2007 is emphasized. An important part of the article presents considerations about the judicial reform of 2008 and about the State and Government regime. The experience of dialogue and political negotiation gained during the last decades, the author concludes, is necessary for the process of Constitutional reform to continue peacefully.

Descriptors: constitutional reform, state reform, Judicial reform, Government and State regimes.

* Investigador emérito en la UNAM, de la cual fue rector, adscrito al Instituto de Investigaciones Jurídicas, donde se desempeñó como director. Presidente del Instituto Iberoamericano de Derecho Constitucional. Agradezco a mis colegas Ricardo Becerra, Edgar Corzo y Diego Valadés las sugerencias que realizaron a este ensayo. Los errores que puedan encontrarse en el mismo son responsabilidad exclusiva del autor. Asimismo, agradezco a Isabel Cacho, mi colaboradora, su acostumbrada eficiencia y dedicación en la transcripción del manuscrito.

Fecha de recepción: 4 de abril de 2008 .

Fecha de dictamen: 14 de julio de 2008 


\section{REFORMAS POLÍTICAS Y ANTECEDENTES DE LA REFORMA DEL ESTADO}

1. La Constitución mexicana de 1917 cumplió, el 1o. de mayo, 91 años de vigencia de regir la existencia del país. Es una ley fundamental, antigua, renovada y actualizada, que ha presidido el mayor desarrollo social, económico y político en la historia de México, aunque aún los rezagos y metas por alcanzar son muchos, nada menos que el cumplimiento cabal de su tesis más importante: la realización de la justicia social.

2. Una Constitución tiene que actualizarse y lo hace a través de los distintos mecanismos que existen para ello y de acuerdo con los procedimientos, circunstancias y tradiciones jurídico-políticas de cada Estado.

El mundo y, claro está, México eran muy diferentes en 1917 al día de hoy. Nuestra Constitución se ha actualizado primordialmente a través del procedimiento de la reforma constitucional, aunque también han estado presentes la interpretación, la costumbre y los usos constitucionales.

El sistema de reforma constitucional que tenemos está inspirado en el norteamericano. Es decir, configura una Constitución rígida. No obstante, en la práctica ha sido y es flexible. ${ }^{1}$ Por décadas, se explicó tal flexibilidad por la existencia de un partido predominante que contaba con las mayorías legislativas para alcanzar la reforma. No obstante, en 1988, dicho partido perdió esa mayoría de las dos terceras partes de los legisladores presentes en el Congreso de la Unión, y el método predominante para actualizar la Constitución continuó y continúa siendo la reforma constitucional, sin desconocer que la interpretación constitucional ha adquirido especial fortaleza y energía desde $1995 .^{2}$

1 Carpizo, Jorge, Estudios constitucionales, 8a. ed., México, Porrúa-UNAM, Instituto de Investigaciones Jurídicas, 2003, pp. 310-317, 443 y 444; Valadés, Diego, La Constitución reformada, México, UNAM, Instituto de Investigaciones Jurídicas, 1987, pp. 14-21; Carbonell, Miguel, Constitución, reforma constitucional y fuentes del derecho, 3a. ed., México, Porrúa, UNAM, Instituto de Investigaciones Jurídicas, 2000, pp. 251-261.

2 Carpizo, Jorge, Temas constitucionales, 2a. ed., México, Porrúa, 2003, pp. 181222; Silva Meza, Juan, "La interpretación constitucional en el marco de la justicia constitucional y la nueva relación entre poderes", en Ferrer Mac-Gregor, Eduardo (coord.), Interpretación constitucional, México, Porrúa-UNAM, Instituto de Investigaciones Jurídicas, 2005, t. II, pp. 1121-1133; Carmona Tinoco, Jorge Ulises, La interpretación judicial constitucional, México, Comisión Nacional de los Derechos Humanos-UNAM, Instituto de Investigaciones Jurídicas, 1996, pp. 191-205. 
Entonces, ¿en dónde se encuentra la flexibilidad real de la rigidez normativa? En el diálogo y la negociación políticas que han permitido a partir de 1988 las coaliciones necesarias para sacar adelante reformas constitucionales precisas.

En algunos países, alcanzar una reforma constitucional es extraordinariamente difícil, lo cual puede incluso resultar negativo para la gobernabilidad democrática. En consecuencia, la situación mexicana goza de aspectos positivos, lo cual no quiere decir que todas esas modificaciones hayan sido acertadas ni que quien esto escribe esté de acuerdo con todas. ${ }^{3}$

3. La modernización de la estructura estatal que acompañó el proceso histórico de la transición democrática, aunque existieron algunos antecedentes, ${ }^{4}$ comenzó en 1977 con la reforma de 17 artículos constitucionales. Los aspectos más importantes de esa reforma política fueron:

a) La aceptación del derecho a la información.

b) La "constitucionalización" de los partidos políticos y los fines que deben perseguir, así como la enumeración de las prerrogativas de las cuales gozan.

c) La introducción de mecanismos de representación proporcional, creándose un sistema mixto con los de la representación clásica o por distrito, al cual puede calificarse de sistema mixto con dominante mayoritario.

d) La entrada automática de los partidos nacionales en las contiendas electorales locales.

e) La representación de las minorías políticas en las entidades federativas y en los municipios.

f) El postulado de procedimientos de gobierno semidirecto en el Distrito Federal; los cuales nunca se materializaron, debido a que la ley respectiva no llegó a expedirse.

g) La Ley Orgánica del Congreso no puede ser vetada por el presidente de la República, ni necesita de la promulgación por parte de éste para tener vigencia.

3 Carpizo, Jorge, Estudios constitucionales, cit., nota 1, pp. 311 y 313.

4 Ibidem, pp. 354-357. 
JORGE CARPIZO

h) La creación de comisiones legislativas de investigación en relación con los organismos descentralizados y empresas de participación estatal mayoritaria. ${ }^{5}$

4. A partir de entonces y hasta 2001, se introdujeron nuevas instituciones en la ley fundamental o se alteró sustancialmente la naturaleza de las que ya existían.

Debe aclararse que respecto a varias de esas instituciones su creación y perfeccionamiento se realizó en diversas etapas y en años subsecuentes. Las más importantes fueron:

a) La conversión de la Suprema Corte de Justicia de la Nación en un Tribunal Constitucional. A pesar de haberse realizado en dos etapas, aún está pendiente la tercera, ${ }^{6}$ a la cual me refiero en el inciso $\left.\left.\left.V, j\right), k\right), 1\right), 11$ ) y $\mathrm{m})$.

b) La judicialización de los actos y conflictos electorales con la creación de tribunales especializados a nivel federal y local. Se realizó en cuatro etapas. ${ }^{7}$

5 Ibidem, pp. 358-405; Rodríguez Araujo, Octavio, La reforma política y los partidos en México, México, Siglo Veintiuno, 1979, pp. 20 y 21; Comisión Federal Electoral, Reforma Política I, México, Gaceta Informativa de la Comisión Federal Electoral, Audiencias Públicas, 1977, pp. 44 y 45, 188, 205 y 206, 234, 286, 291; Comisión Federal Electoral, Reforma Política III, México, Gaceta Informativa de la Comisión Federal Electoral, Reformas a la Constitución, 1978, pp. 47, 227, 265, 270, 308, 313, 315, 318; Reyes Heroles, Jesús, "Estudio preliminar", Mariano Otero, Obras, México, Porrúa, 1967, t. I, pp. 26, 331, 336 y 337.

6 Carpizo, Jorge, Temas constitucionales, op. cit., nota 2, pp. 181-192, 208-222; Fix-Zamudio, Héctor y Valencia Carmona, Salvador, Derecho constitucional mexicano y comparado, 5a. ed., México, Porrúa-UNAM, Instituto de Investigaciones Jurídicas, 2007, pp. 822-833; Corzo Sosa, Edgar, “¿Es la Suprema Corte de Justicia de la Nación un tribunal constitucional?", en Natarén Nandayapa, Carlos F. y Castañeda Ponce, Diana (coords.), La Suprema Corte de Justicia de la Nación en la Reforma del Estado, México, Suprema Corte de Justicia de la Nación-UNAM, Instituto de Investigaciones Jurídicas, 2007, pp. 13-26.

7 Becerra, Ricardo et al., La reforma electoral de 1996. Una descripción general, México, Fondo de Cultura Económica, 1997, pp. 142-187; Melgar Adalid, Mario, "La incorporación del Tribunal Electoral al Poder Judicial de la Federación", 80 Aniversario de la Constitución Política de los Estados Unidos Mexicanos, México, Senado de la República-UNAM, Instituto de Investigaciones Jurídicas, 1995, pp. 207-224; Orozco Henríquez, José de Jesús et al., El sistema mexicano de justicia electoral. Proceso electoral federal 2002-2003, México, Tribunal Electoral del Poder Judicial de la Federación, 2003, pp. 31-48. 
c) La creación de órganos constitucionales autónomos y ciudadanizados para la organización de los procedimientos electorales, tanto a nivel federal como local. Se realizó en cuatro etapas. ${ }^{8}$

d) El establecimiento de un sistema nacional no-jurisdiccional de protección de los derechos humanos. Es la figura del ombudsman; existe una Comisión Nacional, una en el Distrito Federal y una en cada entidad federativa. Se realizó en dos etapas constitucionales y en una previa. ${ }^{9}$

e) La autonomía técnica y funcional del banco central.

f) La creación de los consejos de la Judicatura para responsabilizarse de la administración de los tribunales y de la carrera judicial: ingreso, promoción, ubicación, remuneración y responsabilidad. De nueva cuenta existe un Consejo de carácter federal y la posibilidad de que las entidades federativas también los creen, lo que sólo ha acontecido en cerca de la mitad de ellas. Se realizó en dos etapas, aunque en la segunda, en lugar de perfeccionar la institución, se dieron pasos regresivos. ${ }^{10}$

8 Becerra, Ricardo et al., op. cit., nota precedente, pp. 27-40. Núñez Jiménez, Arturo, El nuevo sistema electoral mexicano, México, Fondo de Cultura Económica, 1991, pp. 107-128. Patiño Camarena, Javier, Derecho electoral mexicano, México, UNAM-Instituto de Investigaciones Jurídicas, 1994, pp. 361-379. Becerra, Ricardo et al., La mecánica del cambio político en México. Elecciones, partidos y reformas, México, Cal y Arena, 2000, pp. 209-362 y 402-403.

9 Carpizo, Jorge, Derechos humanos y ombudsman, 3a. ed., Porrúa-UNAM, Instituto de Investigaciones Jurídicas, 2003, pp. 81-86; Stein Velasco, José Luis, "La reforma constitucional en materia de derechos humanos", Reformas constitucionales y modernidad nacional, México, Porrúa, 1992, p. 102; Fix-Zamudio, Héctor, "Artículo 102, apartado $\mathrm{B}$, de la Constitución federal mexicana. Constitucionalización del ombudsman en el ordenamiento mexicano", La modernización del derecho constitucional mexicano. Reformas constitucionales 1990-1993, México, UNAM, 1994, pp. 147-188; Aguilar Cuevas, Magdalena, El defensor del ciudadano (ombudsman), México, Comisión Nacional de los Derechos Humanos-UNAM, Facultad de Derecho, 1991, pp. 134-146; Armienta Calderón, Gonzalo M., El ombudsman y la protección de los derechos humanos, México, Porrúa, 1992, pp. 55-73.

10 Carpizo, Jorge, Estudios constitucionales, op. cit., nota 1, pp. 192-197; Fix-Zamudio, Héctor, "Órganos de dirección y administración de los tribunales en los ordenamientos latinoamericanos", Memoria de El Colegio Nacional, México, 1992, pp. 43 y 44; Fix-Zamudio, Héctor y Fix-Fierro, Héctor, El Consejo de la Judicatura, México, UNAM, Instituto de Investigaciones Jurídicas, 1996, pp. 61-70; Melgar Adalid, Mario, El Consejo de la Judicatura Federal, México, Porrúa, 1998, pp. 71-92, 117-140. 
g) Reglas más claras y equitativas para el procedimiento electoral, especialmente en lo relativo a los medios electrónicos y al financiamiento de los partidos. Se realizó en dos etapas.

h) La autonomía técnica de un órgano, dentro de la Cámara de Diputados, para fiscalizar las cuentas de la gestión económica del Estado, del sector público y de los recursos públicos manejados por los particulares. Algún día habrá de convertirse en un órgano constitucional autónomo. ${ }^{11}$

i) Elecciones para elegir a los poderes Ejecutivo y Legislativo del Distrito Federal. La naturaleza y funciones de este último órgano se ha realizado en varias etapas. ${ }^{12}$

j) La declaración de la composición pluricultural de la nación y la enumeración de los derechos de los pueblos indígenas, de algunos de los cuales deben establecerse sus características en las Constituciones de las entidades federativas. ${ }^{13}$

k) Ampliación del catálogo de los derechos fundamentales y sus garantías, como: el principio de no-discriminación, el derecho al trabajo

11 Vera Santos, José Manuel, El Tribunal de Cuentas y los órganos de control externo de las comunidades autónomas, Madrid, Centro de Estudios Políticos y Constitucionales, 2001, pp. 41-69; Gómez Sánchez, Yolanda, El Tribunal de Cuentas. El control económico-financiero externo en el ordenamiento constitucional español, Madrid, Marcial Pons, 2001, pp. 39-63; Crespo, José Antonio, Fundamentos políticos de la rendición de cuentas, México, Cámara de Diputados, 2001, pp. 9 y 21; Ugalde, Luis Carlos, La rendición de cuentas en los gobiernos estatales y municipales, México, Cámara de Diputados, 2002, pp. 7, 10, 11, 27, 31, 35; Hernández, María del Pilar, "Comentario al artículo 79”, Constitución Política de los Estados Unidos Mexicanos. Comentada y concordada, 19a. ed., México, Porrúa-UNAM, Instituto de Investigaciones Jurídicas, 2006, t. III, pp. 369-382.

12 Becerra, Ricardo et al., op. cit., nota 7, pp. 215-220; Fix-Zamudio, Héctor y Valencia Carmona, Salvador, op. cit., nota 6, pp. 1029-1037; De Andrea Sánchez, Francisco J., "El hilo conductor de las reformas constitucionales electorales en México 1946-1996", 80 Aniversario de la Constitución Política de los Estados Unidos Mexicanos, cit., nota 7, pp. 41 y 42.

13 Carbonell, Miguel, "Comentario al artículo 2o.", Constitución Política de los Estados Unidos Mexicanos. Comentada y concordada, 19a. ed., cit., nota anterior, t. I, pp. 19-51; Madrazo Jorge, "La adición al artículo 4o. constitucional en materia indígena”, La modernización del derecho constitucional mexicano. Reformas constitucionales 1990-1993, México, UNAM, Instituto de Investigaciones Jurídicas, 1994, pp. 191-202; González Galván, Jorge Alberto (coord.), Constitución y derechos indígenas, México, UNAM, Instituto de Investigaciones Jurídicas, 2002, p. 287; véase especialmente los ensayos de Gilberto López y Rivas, Francisco López Barcenas, Manuel González Oropeza y del propio Jorge Alberto González Galván. 
digno y socialmente útil, la protección de la salud, vivienda digna y decorosa; derecho a un medio adecuado, derechos de la niñez, catálogo de derechos de la víctima o del ofendido, fórmulas sobre la libertad provisional bajo caución, mayores garantías de seguridad jurídica durante el proceso penal, impugnación jurisdiccional de las resoluciones del ministerio público sobre el no-ejercicio y el desistimiento de la acción penal, responsabilidad objetiva y directa del Estado por los daños que cause en los bienes o derechos de los particulares. ${ }^{14}$

1) Reconocimiento de la competencia jurisdiccional de la Corte Interamericana de Derechos Humanos y de la Corte Penal Internacional. ${ }^{15}$

5. Durante el sexenio 2000-2006 la reforma más importante, además del reconocimiento de algunos derechos humanos, fue la aprobación de la Ley Federal de Transparencia y Acceso a la Información Pública Gubernamental" de 2002, que fue impulsada por grupos sociales que presentaron una iniciativa al Congreso. La ley garantiza el acceso de toda persona a la información en posesión de los poderes federales, los órganos constitucionales autónomos, órganos con autonomía legal y cualquier otra entidad federal.

Dicha Ley persigue que el gobierno y los órganos federales entreguen información sobre su manera de trabajar, el uso de los recursos públicos y sus resultados, salvo la información reservada o confidencial de acuerdo con las disposiciones de la propia Ley.

14 Carbonell, Miguel, Los derechos fundamentales en México, UNAM, Instituto de Investigaciones Jurídicas, 2004, pp. 184-194, 816-826, 879-905; Rey, Fernando, El derecho fundamental a no ser discriminado, Madrid, McGraw-Hill, 1995, p. 64; véase los interesantes artículos contenidos en Muñoz de Alba Medrano, Marcia (coord.), Temas selectos de salud y derecho, México, UNAM, Instituto de Investigaciones Jurídicas, 2002, p. 222; Fix-Zamudio, Héctor y Valencia Carmona, Salvador, op. cit., nota 6, pp. 437-469; Quintana Roldán, Carlos F. et al., Derechos humanos, 4a. ed., México, Porrúa, 2006, pp. 37-50.

15 Sobre la Corte Interamericana resulta muy útil consultar la obra intitulada $\mathrm{La}$ Corte Interamericana de Derechos Humanos. Estudios y documentos, San José, Costa Rica, Instituto Interamericano de Derechos Humanos, s/f, $339 \mathrm{pp}$. Buergenthal, Thomas, "Implementation in the Interamerican Human Rights System", en Bernhardt, F. y Jolowics, J. A. (eds.), International Enforcement of Human Rights, Berlín-Heidelberg, Springer Verlag, 1987, p. 69. 
Para aplicar y hacer vigentes las normas de la Ley se creó el Instituto Federal de Acceso a la Información Pública (IFAI), como un órgano con autonomía operativa, presupuestaria y de decisión. ${ }^{16}$

6. Nótese que las reformas fueron abundantes e importantes, y que en varias ocasiones se realizaron en varias etapas y a través de los años, por muy diversas razones. Un ejemplo es la conversión de la Suprema Corte en Tribunal Constitucional. Pesaba en contra de esta conversión la tradición jurídica mexicana en la cual la Suprema Corte desempeñaba tanto funciones constitucionales como las de una corte de casación, la oposición del Poder Judicial Federal a la reforma porque sentía que la Suprema Corte perdía facultades y existía el temor a la estabilidad de los propios ministros de aquélla, y que a ese alto tribunal se le suprimieran sus atribuciones respecto a la administración de la carrera judicial federal. Fue necesaria una larga labor de convencimiento y negociación con diversos sectores jurídicos, especialmente con la mencionada Suprema Corte.

Otro ejemplo claro lo constituye el actual sistema electoral, con sucesivas reformas que implicaron un proceso paulatino de madurez y de asimilación de experiencias, que condujeron al diálogo, la negociación y las modificaciones constitucionales. Es decir, las reformas no fueron pensadas en laboratorios o gabinetes, sino que se elaboraron al calor de las coyunturas, las exigencias políticas y sociales, y respondieron a la creciente pluralidad de la sociedad.

\section{LA LEY PARA LA REFORMA DEL ESTADO DE 2007}

1. A partir de 1998, existen cuando menos tres ejercicios o consultas para realizar modificaciones constitucionales, enmarcadas en una reforma del Estado.

La LVII Legislatura de la Cámara federal de Diputados convocó a foros regionales para que la sociedad se pronunciara sobre nuestra Constitución.

16 Instituto Federal de Acceso a la Información Pública, Transparencia, acceso a la información y datos personales, México, IFAI, 2003, 139 pp. En el número 7 de Comparative Media Law Journal, México, Fundación Konrad Adenauer-UNAM, Instituto de Investigaciones Jurídicas, 2006, se encuentran artículos muy interesantes sobre el acceso a la información pública en Chile, España y Perú. 
Al término de ese ejercicio se habían presentado 730 ponencias y se proponía la modificación de 122 artículos constitucionales. ${ }^{17}$

A partir de septiembre de 2000, se reunió la Comisión de Estudios para la Reforma del Estado, que había sido instalada el anterior 21 de agosto por Vicente Fox, quien había ganado las elecciones presidenciales. Esa Comisión fue coordinada por Porfirio Muñoz Ledo; se formaron seis mesas de trabajo, subdivididas en cinco temas cada una, y participaron 167 ponentes.

El número de propuestas fue inmenso; en diversas ocasiones, las ponencias discreparon y no fue posible alcanzar consenso. Dicho ejercicio no prosperó. ${ }^{18}$

En marzo de 2001, la Secretaría de Gobernación convocó al Foro para la Revisión Integral de la Constitución, mismo que se subdividió en foros o grandes temas, los que, a su vez, se desarrollaron en diversas mesas, durante seis meses.

Se celebraron 51 sesiones tanto en la ciudad de México, como en otras ciudades de la República, se presentaron 324 trabajos escritos. Se propusieron reformas o adiciones a 75 artículos constitucionales. Dichos foros se caracterizaron por haber gozado de amplia difusión en los medios de comunicación. ${ }^{19}$

Cómo es fácil constatar, el debate se prolongó durante varios años, sin aparente resultado. No obstante, el tiempo no se perdió, debido a que las ideas se fueron depurando, y las propuestas se han considerado y meditado con más cuidado. Además, el tiempo ha sido uno de los factores que han influido para que las más importantes fuerzas políticas lleguen a consensos, debido a que la opinión pública rechazaba que el Congreso estuviera inmovilizado, se tenía la percepción de que los legisladores no trabajaban, lo cual no era completamente cierto, y que les interesaban más

17 Carpizo, Jorge, Concepto de democracia y sistema de gobierno en América Latina, México, UNAM, Instituto de Investigaciones Jurídicas, 2007, pp. 134 y 135.

18 Muñoz Ledo, Porfirio (coord.), Comisión de Estudios para la reforma del Estado. Conclusiones y propuestas, México, UNAM, 2002, pp. 292.

19 Agradezco al doctor Francisco Valdés Ugalde la amplia información que me proporcionó respecto al desarrollo de esos foros, contenida en un CD. El doctor Valdés Ugalde fue el responsable de la organización de aquéllos, en su entonces carácter de director del Instituto Nacional de Estudios Históricos de la Revolución Mexicana. 
sus intereses partidistas y particulares que los de la nación, lo cual desprestigió al Congreso de la Unión. ${ }^{20}$

2. Otra de las razones por las cuales la Reforma del Estado se encontraba paralizada eran los desencuentros entre los poderes Ejecutivo y Legislativo federales, en este último prevalece el pluralismo y la competencia democrática. En varias ocasiones, durante el sexenio 2000-2006, el presidente de la República, incluso ofendió y criticó al Congreso de la Unión.

El senador Manlio Fabio Beltrones, al hacerse cargo de esos antecedentes y en su carácter de coordinador de los senadores del PRI, presentó el 14 de noviembre de 2006 un proyecto para crear la Ley para la Reforma del Estado.

Dicho proyecto, con modificaciones, se convirtió en norma jurídica y fue publicada en el Diario Oficial de la Federación del 13 de abril de 2007.

Los aspectos sobresalientes de dicha Ley son:

a) Se estableció una metodología para el trabajo, negociación y la formación de consensos que se traduzcan en acuerdos de reformas, así como un plazo para alcanzarlos.

b) Se creó la Comisión Ejecutiva de Negociación y Construcción de Acuerdos del Congreso de la Unión como el órgano rector de la conducción del proceso de Reforma del Estado, y se crearon subcomisiones.

c) Se precisaron las etapas que habrían de desarrollarse para la negociación y la construcción de acuerdos.

d) Se estableció que la agenda sobre la que tenían que pronunciarse el Poder Legislativo, los grupos parlamentarios y los partidos políticos nacionales, se integraría prioritariamente con seis grandes temas: régimen de Estado y gobierno, democracia y sistema electoral, federalismo, Poder Judicial, reforma hacendaria y garantías sociales.

e) La vigencia de la ley sería de doce meses, a partir de su publicación en el Diario Oficial. Es decir, hasta el 13 de abril de 2008.

20 Parás, Pablo et al., Cultura política de la democracia en México: 2006. Barómetro de las Américas, México, Data Opinión Pública y Mercados, 2006, pp. 78-80, 129-130. Consulta Mitofsky. Roy Campos Research, Confianza en las instituciones. Ranking nacional, México, Tracking poll. Roy Campos, 2008, pp. 1-7, www.consulta. com.mx. 
3. Esta Ley recibió diversas críticas, como que era innecesaria para poder legislar, que su contenido era superfluo porque las reglas del procedimiento legislativo ya se encontraban precisadas, que resultaba absurdo que el legislador autoestableciera términos para ejercer sus funciones.

A su vez, dicha Ley fue defendida con argumentos. Los míos fueron: se llevaba un periodo de diez años discutiendo una Reforma del Estado, y no existía casi resultado alguno, era una importante manifestación de voluntad política por parte del Poder Legislativo y un compromiso político para alcanzar acuerdos, ciertamente se podía haber seguido otro camino, pero que el de la mencionada Ley era el más fuerte y poderoso, y se justificaba por los casi diez años de inamovilidad legislativa en este tema, que se establecía una metodología con etapas precisas y se asignaban recursos para el trabajo de apoyo, que el plazo serviría para que el nuevo ejercicio no fuera a dormir el sueño de los justos como sus antecesores en esos diez años anteriores.

Los resultados que se han alcanzado en el año de vigencia de la mencionada Ley ratifican que la razón jurídica y política la tenía el Congreso de la Unión y quienes defendimos dicha norma, los antiformalistas, pero exigiendo pleno respeto a la Constitución, tal y como aconteció.

\section{LAS REFORMAS DE ACCESO A LA INFORMACIÓN Y LA ELECTORAL DE 2007}

1. La LX Legislatura del Congreso de la Unión ha logrado que la $R e$ forma del Estado camine.

Casi simultáneamente en toda la República, con el procedimiento de la Ley para la Reforma del Estado, se vino discutiendo una modificación constitucional para garantizar el derecho de acceso a la información, en virtud de que las legislaciones de las entidades federativas sobre la materia eran muy diversas, heterogéneas y desiguales. En algunos casos más que una garantía a dicho derecho resultaba una restricción al mismo y, en otros, únicamente era una simulación para de plano anularlo.

Además, toda esa heterogeneidad lesionaba el derecho de las personas que solicitaban información, en virtud de que los procedimientos, los límites, la apertura y los documentos disponibles eran de la gama más diversa y variada. Así, un derecho fundamental se protegía en forma por 
demás desigual, dependiendo de la entidad federativa en la cual se realizaba la solicitud de acceso a la información. Como consecuencia surgió la inquietud de si un derecho fundamental puede diferenciar a los mexicanos por razón del lugar de su nacimiento o residencia.

La idea, entonces, concretada en un anteproyecto firmado por varios gobernadores pertenecientes a los tres principales partidos políticos y apoyada por el IFAI, fue y es que la Constitución establezca una serie de principios y bases, que la Federación, los estados y el Distrito Federal habrán de respetar al legislar sobre el derecho de acceso a la información.

Dicha reforma constitucional se publicó en el Diario Oficial de la $\mathrm{Fe}$ deración del 20 de julio de 2007; en la misma se agregan varios párrafos al artículo sexto de la ley fundamental.

Los más importantes de esos principios y bases son:

a) Toda la información que producen y en manos de autoridad o entidad federal, estatal o municipal es pública y sólo puede ser reservada temporalmente por razones de interés público. La persona, si se le niega la información, tiene los medios de defensa para impugnar la decisión del órgano público que se la denegó.

b) La información respecto a la vida privada y datos personales se encuentra protegida en los términos y excepciones que determine la Ley.

c) Toda persona, sin necesidad de acreditar interés alguno o justificar su utilización, tiene acceso gratuito a la información pública y a sus datos personales.

d) Se establecen órganos especializados, con autonomía operativa, de gestión y de decisión para la revisión y el aseguramiento de dichos derechos.

e) Las autoridades y entidades correspondientes deben preservar sus documentos en archivos actualizados y habrán de publicar en medios electrónicos sus indicadores de gestión y el ejercicio de los recursos públicos.

Ricardo Becerra y Sergio López-Ayllón, dos de los principales especialistas en la materia, cuya participación durante el procedimiento de la reforma al artículo 6o. constitucional fue trascendente, afirman, y con razón, que:

Si se mira bien, si se extraen las consecuencias lógicas y políticas, el nuevo texto de la Constitución implica una auténtica revolución institucional. En 
México, la transparencia ya no puede ser entendida como trámite accesorio, trabajo adicional o monserga diaria para funcionarios, sino que induce otra pauta al trabajo, otra forma de organización administrativa y más allá, un nuevo valor para la política y el servicio público.

Las instituciones gubernamentales deberán "producir" información sobre el ejercicio de los recursos, sobre sus funciones, los resultados que obtienen y las razones de sus decisiones. La mecánica es simple pero subversiva: quedan obligadas a documentar todo acto que derive de sus facultades, competencias y funciones, incluso de los procesos deliberativos. ${ }^{21}$

2. Las principales reformas electorales en los últimos 20 años fueron las de 1990, 1993, 1994 y 1996. Las elecciones federales de 2006 se mostraron muy disputadas y exhibieron que la legislación respectiva adolecía de graves deficiencias en algunos aspectos, como el de equidad en el uso de los medios electrónicos durante la campaña electoral. El periodo poselectoral fue especialmente difícil y complicado a grado tal que se temió que la paz pública podría verse en peligro.

Para superar esas deficiencias y tratar de asegurar que no vuelva a presentarse un conflicto poselectoral tan complicado, los partidos políticos se abocaron a construir una nueva reforma electoral, la cual alteró nueve artículos constitucionales. Dichas modificaciones se publicaron en el Diario Oficial de la Federación del 13 de noviembre de 2007, y sus principales disposiciones son:

a) El establecimiento del derecho de réplica en los medios de comunicación.

b) La prohibición expresa a la intervención de organizaciones gremiales en la creación de partidos, así como a cualquier forma de afiliación corporativa.

c) Nuevas reglas para el financiamiento de los partidos políticos, tanto respecto al público como el correspondiente al privado.

21 Becerra, Ricardo y López Ayllón, Sergio, "Transparencia: horas decisivas", Periódico Reforma, Enfoque, México, 13 de abril de 2008, p. 7; véase Becerra, Ricardo y Lujambio, Alonso, "Por qué constitucionalizar", en López-Ayllón, Sergio (coord.), Democracia, transparencia y Constitución, México, IFAI-UNAM, Instituto de Investigaciones Jurídicas, 2007, pp. 173-197; Gómez Gallardo, Perla y Villanueva, Ernesto, Indicadores de transparencia y reforma del artículo 6o. constitucional, México, Trust, 2007, p. 195. 
d) Límites a las erogaciones en los procesos internos de selección de candidatos y a las campañas electorales de los partidos políticos.

e) La Ley establecerá los supuestos en los cuales los bienes y remanentes de los partidos políticos que pierdan su registro, deban ser adjudicados a la Federación.

f) Reglas precisas para el uso de los medios de comunicación por parte de los partidos políticos, tanto de manera permanente como durante las precampañas y campañas electorales.

g) Los partidos políticos no podrán contratar o adquirir tiempos en cualquier modalidad de radio y televisión. Tampoco nadie lo podrá hacer para influir en las preferencias electorales de los ciudadanos, ni a favor o en contra de algún partido político o candidato, con lo que se establece una nueva relación entre el Estado, la sociedad, los partidos políticos y los medios.

h) Para los fines electorales en las entidades federativas, el Instituto Federal Electoral (IFE) administrará los tiempos que corresponden al Estado en los medios electrónicos.

i) Los partidos políticos deberán abstenerse de expresiones que denigren a las instituciones y a los propios partidos políticos, o que calumnien a las personas.

j) Reducción de la duración de las campañas y precampañas electorales.

k) Los consejeros electorales serán renovados en forma escalonada, y desaparece la figura del sustituto de consejero.

l) Los consejeros electorales y el secretario ejecutivo no podrán ocupar, dentro de los dos años siguientes a la fecha de su retiro, cargos en los poderes públicos en cuya elección hayan participado.

li) Se crea un órgano técnico con autonomía de gestión del Consejo General del IFE para la fiscalización de las finanzas de los partidos políticos nacionales, cuyo titular será designado por el propio Consejo General. Este órgano técnico no estará limitado por los secretos bancario, fiduciario y fiscal.

m) Se suprime la función de investigación de la Suprema Corte de Justicia en relación con la violación del voto público.

n) El Tribunal Electoral, la sala superior y las regionales, únicamente podrán declarar la nulidad de una elección por las causales que expresamente se establezcan en las leyes. 
ñ) El recurso correspondiente en contra de las decisiones de las autoridades electorales locales procederá solamente cuando la reparación solicitada sea material y jurídicamente posible dentro de los plazos electorales y sea factible antes de la fecha constitucional o legalmente fijada para la instalación de los órganos o la toma de posesión de los funcionarios elegidos.

o) Las salas del Tribunal Electoral podrán resolver la no aplicación de leyes sobre la materia electoral contrarias a la Constitución, limitándose al caso concreto sobre el cual verse el juicio.

p) Las nuevas reglas electorales a nivel federal se aplicarán, asimismo, a nivel local.

q) La ley local señalará los supuestos y las reglas para la realización, en las esferas administrativa y jurisdiccional, de recuentos totales o parciales de votación.

r) La obligación de celebrar las jornadas electorales de los estados el primer domingo de julio del año correspondiente, menos si dicha jornada se celebra en el año de los comicios federales y no coincide en la misma fecha de estos últimos.

s) La propaganda de comunicación social de los poderes públicos, órganos autónomos y entidades públicas de los tres órdenes de gobierno, no podrá implicar promoción personalizada de ningún servidor público.

Ahora bien, existen dos aspectos de esta reforma que me preocupan:

t) El nombramiento del titular de la Contraloría General del IFE por parte de la Cámara de Diputados, en virtud de que la intervención del órgano legislativo puede llegar a afectar la autonomía de dicho Instituto, a pesar de que dicho nombramiento será con el voto de las dos terceras partes de los legisladores presentes y a propuesta de instituciones públicas de educación superior.

u) El IFE podrá asumir la organización de procesos electorales locales, si así lo solicitan las autoridades competentes de las entidades federativas. Esta disposición puede ser el principio de la centralización de todos los procesos electorales en el país, despojando de esta facultad a los estados de la República. ${ }^{22}$

22 Córdova Vianello, Lorenzo, "La nueva reforma electoral", Nexos, México, vol. XXIX, año 29, núm. 358, octubre de 2007, pp. 6-8; Murayama, Ciro, "Consecuencias económicas de la reforma electoral”, en el mismo núm. de Nexos, pp. 9-11; Alcocer, Jorge, "Tramo final”, Voz y Voto, México, núm. 180, febrero de 2008, pp. 66-69; en el mis- 
3. Ahora bien, la reforma electoral es altamente positiva; responde a necesidades y experiencias concretas que se han presentado en las campañas y comicios electorales, principalmente en los ya mencionados de carácter federal de 2006.

Esta reforma es producto de un proceso de maduración, como ya asenté, que se inició en 1977, y se aceleró en 1990, 1993, 1994 y 1996. Esta reforma implica la culminación de una de las etapas de nuestra transición a la democracia, y constituye uno de los seis rubros contenidos en la Ley para la Reforma del Estado.

No obstante, esta reforma de 2007 ha sido muy atacada y criticada, en virtud de los inmensos intereses que lesiona. Un solo ejemplo basta para la comprensión cabal de la aseveración anterior. El financiamiento público que los partidos políticos recibieron durante las campañas electorales federales de 2006 fue de un poco más de dos mil millones de pesos. De esa cantidad, el 95\%, más de 1,900 millones de pesos, se gastó en los medios electrónicos (radio y televisión). ${ }^{23}$ Además, las confederaciones y asociaciones de empresarios y de industriales desean seguir teniendo especial influencia en los comicios, precisamente a través de propaganda pagada en los medios electrónicos. ¿Cuántos organismos o personas más pueden pagar los altísimos costos de dicha propaganda en los citados medios?

\section{LA REFORMA JUDICIAL}

1. Aunque se le ha denominado "reforma judicial", sus finalidades son primordialmente la instauración del sistema procesal penal, oral y acusatorio, la concesión de mayores medios al Estado para combatir el crimen organizado, la ampliación de derechos en el proceso penal y diversos aspectos relacionados con el Ministerio Público. En realidad, persigue ser una reforma integral del sistema de justicia penal. No toca aspectos es-

mo núm. de Voz y Voto, Murillo Karam, Jesús, "Reforma electoral 2007”, pp. 74-76. Berrueto, Federico, "Murallas partidistas", Voz y Voto, México, núm. 181, marzo de 2008, pp. 19-23.

23 Córdova Vianello, Lorenzo y Murayama Rendón, Ciro, "El financiamiento y el acceso de los partidos políticos a los medios de comunicación en México. La reforma electoral de 2007 en la Constitución y sus efectos en las leyes locales", ponencia presentada en el Primer Congreso Internacional de Ciencia Política "Gobierno y democracia sin fronteras", Mexicali, 2008, p. 11. 
tructurales del Poder Judicial, ni varios de sus graves problemas actuales, ${ }^{24}$ aunque incide en su estructura al crear los jueces de control y los juicios orales.

En la actualidad, el Congreso de la Unión ha aprobado la reforma, en virtud de que el Senado, el 28 de febrero de 2008, estuvo de acuerdo con la última alteración sancionada por la Cámara de Diputados. En tal virtud, el proyecto de decreto se turnó a la consideración de las legislaturas de las entidades federativas, de acuerdo con el procedimiento de reforma constitucional que establece el artículo 135 de la ley Fundamental.

Es probable que hasta el día de hoy este proyecto de "reforma judicial" sea el más trascendente dentro de la Reforma del Estado. Para su elaboración se presentaron diversas iniciativas por parte del presidente de la República, numerosos diputados pertenecientes a seis partidos políticos y un ciudadano. ${ }^{25}$

En forma paralela a la discusión legislativa, se llevó a cabo una discusión por parte de organizaciones no-gubernamentales, medios de comunicación y académicos que influyó, en parte, en la propia labor legislativa.

Los principales aspectos de la reforma judicial, que modifica los artículos 16, 17, 18, 19, 20, 21, 23; las fracciones XXI y XXIII del artículo 73; la fracción VII del artículo 115 y la fracción XIII del apartado B del artículo 123 constitucionales, son los siguientes:

a) Por primera vez se define a nivel constitucional el concepto de delincuencia organizada. No obstante, es una definición tan amplia que se vuelve imprecisa y, por ende, puede resultar peligrosa para las libertades.

b) Se crean dos derechos penales, el que puede llamarse ordinario, con amplias garantías, que se enriquece con nuevos derechos; y otro, de carácter excepcional para el crimen organizado, con garantías reducidas o "recortadas", cuyo origen se encuentra en la Ley Federal contra la Delincuencia Organizada de 1996 que implantó una ruta desgarantizadora. ${ }^{26}$ Existe preocupación, que yo comparto, de que el Derecho Penal excepcional se vaya a convertir en el ordinario o que, por razones extrajurídicas,

24 Carpizo, Jorge, Concepto de democracia y sistema de gobierno en América Latina, cit., nota 17, pp. 137-144.

25 Cámara de Diputados, Gaceta Parlamentaria, núm. 2401-VIII, 11 de diciembre de 2007 http://gaceta.diputados.gob.mx/Gaceta/60/2007/dic/20071211-VIII.html, pp. 1-3.

26 García Ramírez, Sergio, "Un cambio con sabor a veneno", El Universal, 22 de febrero de 2008, p. A14. Del mismo autor, Delincuencia organizada, 3a. ed., México, Porrúa-UNAM, Instituto de Investigaciones Jurídicas, 2002, pp. 89-215. 
algún o algunos casos ordinarios se consideren excepcionales, a lo que se presta la definición tan amplia de crimen organizado.

c) La figura del arraigo de una persona se introduce a la Constitución para delitos de delincuencia organizada hasta por cuarenta días, los que podrán prorrogarse hasta 80 . El arraigo lo decreta el juez a petición del Ministerio Público.

d) Se establece el juez de control como la autoridad que resolverá las solicitudes de medidas cautelares, providencias precautorias y técnicas de investigación de la autoridad, que necesiten control judicial.

Asimismo, el juez de control desahogará las audiencias del proceso preliminares al juicio, y la resolución de las impugnaciones contra las determinaciones del Ministerio Público.

e) Se dispone que las leyes preverán mecanismos alternativos de solución de controversias. En materia penal, la norma secundaria asegurará la reparación del daño y establecerá los casos en los cuales será necesaria la supervisión judicial.

f) La existencia de un servicio de defensoría pública de calidad. Los defensores contarán con un servicio profesional de carrera y sus percepciones no serán menores a las de los agentes del Ministerio Público.

En consecuencia, se suprime como defensor a una "persona de confianza", que únicamente se presta a corrupción y falta de profesionalismo.

g) Se constitucionaliza la existencia de reclusorios de alta seguridad en materia de delincuencia organizada y para otros internos, en donde se podrán restringir una serie de derechos.

h) Se disminuye en forma notable el nivel probatorio para que el Ministerio Público solicite al juez una orden de aprehensión.

Se sustituye el concepto de cuerpo del delito y probable responsabilidad del indiciado por el de "los datos que establezcan que se ha cometido un hecho que la ley señale como delito y que exista la probabilidad de que el indiciado lo cometió o participó en su comisión".

El auto de formal prisión se remplaza por un auto de vinculación a proceso.

Con estos cambios se persiguen varias finalidades: abatir los casos de la prisión preventiva, aunque sí se contemplan otras medidas cautelares; que el vinculado a proceso conozca los medios probatorios que el Ministerio Público considera que le incriminan para poder preparar mejor su 
defensa, que al disminuirse las exigencias probatorias para la intervención del juez, se facilite la investigación y el imputado pueda hacer valer sus derechos ante el juez y ya no ante su acusador; que el Ministerio Público pueda allegarse medios probatorios aunque el caso se encuentre en la competencia del juez, y no tendrá que acreditar de antemano la probable responsabilidad del inculpado, ${ }^{27}$ y en tal virtud se eliminan las garantías en la investigación ministerial, debido a que ésta se convierte de carácter preliminar en lugar de seudojudicial.

El peligro de estas nuevas disposiciones es que se multipliquen en forma inconmensurable las órdenes de aprehensión, las "puestas a disposición del juez", y que lo mismo acontezca con la "vinculación a proceso". Podría acontecer que una orden, una puesta y una vinculación no se le niegue a nadie. Empero, hay que tener en cuenta que esa orden, esa puesta y esa vinculación no son inofensivas, y pueden ocasionar graves consecuencias jurídicas, laborales, económicas, sociales, familiares y sicológicas a las personas, aunque con posterioridad se les declare inocentes.

No obstante, la exposición de motivos del proyecto considera que no se presentará tal peligro. Textualmente se asienta que:

No existe un riesgo de que esta reducción del nivel de prueba necesario para la emisión de la orden de aprehensión sea motivo de abusos, porque existen amplios contrapesos que desalentarán a quienes se sientan tentados de ello, en razón de que el proceso penal será totalmente equilibrado para las partes y respetará cabalmente los derechos del inculpado, de manera que si se obtiene una orden de captura sin que los indicios existentes puedan alcanzar en forma lícita el estatus de prueba suficiente, sin temor a dudas se absolverá al imputado, al incorporarse expresamente a la Constitución principios como el de presunción de inocencia, el de carga de la prueba y el de exclusión de prueba ilícitamente obtenida.

Dicho de otra manera, sería contraproducente para el Ministerio Público solicitar la orden de aprehensión sin tener altas probabilidades de poder acreditar el delito y la responsabilidad penal en el juicio; en razón de que ya no tendrá otra oportunidad de procesar al imputado. ${ }^{28}$

27 Cámara de Diputados, Gaceta Parlamentaria..., cit., nota 25, p. 4.

28 Ibidem, pp. 16 y 17. 
En consecuencia, el Ministerio Público — afirman los legisladoresya no tendrá que acreditar el cuerpo del delito ni la probable responsabilidad del inculpado.

Ojalá que así vaya a funcionar en la realidad, pero guardo inquietudes. Cuando exista una posible restricción a la libertad, la autoridad debe actuar dentro de márgenes muy precisos, sin ambigüedad alguna. Todas las reformas anteriores fracasaron primordialmente debido al factor humano, de lo que haré una breve reflexión más adelante.

i) Se numeran restrictivamente los casos en los cuales el Ministerio Público puede solicitar la prisión preventiva al juez, y aquellos en que el juez la debe ordenar de oficio como en los asuntos de delincuencia organizada, homicidio doloso, violación, secuestro, etcétera. Es la propia Constitución la que está señalando el catálogo de los delitos graves.

j) Tratándose de delincuencia organizada, si el inculpado evade la acción de la justicia después de la emisión del auto de vinculación a proceso, o es puesto a disposición de otro juez que lo reclama en el extranjero, se suspenden el proceso y los plazos para la prescripción de la acción penal.

k) El proceso penal será acusatorio y oral, y se regirá por los principios de publicidad, contradicción, concentración, continuidad e inmediación. Se establecen los principios generales de ese proceso oral, entre los cuales resalto: toda audiencia se desarrollará en presencia del juez quien no puede delegar el desahogo y la valoración de las pruebas; el juicio se celebrará ante juez que no haya conocido del caso previamente, o sea, diverso del juez de control; la presentación de los argumentos y pruebas será de manera pública, contradictoria y oral; en ciertos supuestos el juicio puede terminar anticipadamente; la ley precisará los beneficios que se pueden otorgar al inculpado que acepte su responsabilidad; cualquier prueba obtenida con violación de derechos fundamentales es nula; el juez no habrá de tener contacto con alguna de las partes sin la presencia de la otra, por razones de igualdad hacia la parte más débil y para que no obtenga ninguna información unilateral.

Una de las razones que se han expuesto para la implantación de los juicios orales se encuentra en un muestreo representativo realizado en los centros de readaptación social de los estados de México y Morelos y en el Distrito Federal, el que mostró que el 80\% de los imputados nunca tuvo contacto oral alguno con el juez. 
l) Se presume la inocencia de toda persona imputada mientras no se declare su responsabilidad en una sentencia.

ll) En delincuencia organizada el juez podrá autorizar que se mantenga en reserva el nombre y datos del acusador, y los beneficios a favor del inculpado, procesado o sentenciado que preste ayuda eficaz en la investigación y persecución de ese tipo de delitos.

m) En delincuencia organizada, las actuaciones en la fase de investigación podrán tener valor probatorio, cuando no se puedan reproducir en el juicio, o exista riesgo para los testigos o las víctimas. El inculpado las puede objetar, impugnar o aportar pruebas en contrario.

n) Sólo se puede ser juzgado por un juez o tribunal. En consecuencia, desaparece el jurado de ciudadanos. Las audiencias serán públicas salvo en casos de excepción.

o) La prisión preventiva no podrá exceder de dos años, a menos que su prolongación se deba al ejercicio de defensa del imputado. Cumplido ese término y si no existe sentencia, se le pondrá en libertad de inmediato, aunque otras medidas cautelares se le puedan imponer.

p) El Ministerio Público deberá garantizar la protección de víctimas, ofendidos, testigos y todos los sujetos que intervengan en el proceso.

q) Se adiciona a las impugnaciones ante autoridad judicial de los actos del Ministerio Público, sus omisiones durante la investigación de los delitos.

r) Señala que la investigación de los delitos corresponde al Ministerio Público y a las policías, las cuales actuarán bajo la conducción y mando de aquél. Actualmente el dispositivo constitucional establece que el Ministerio Público "se auxiliará de la policía que estará bajo su autoridad y mando inmediato". Ésta es una modificación de gran tonelaje que va contra las experiencias positivas en el derecho comparado). ${ }^{29}$ Como bien dice Sergio García Ramírez, se diluye la jerarquía que debe existir entre dichos cuerpos, y se crea una nueva relación entre el Ministerio Público y

29 Carpizo, Jorge, Propuestas sobre el Ministerio Público y la función de investigación de la Suprema Corte, México, Porrúa-Instituto Mexicano de Derecho Procesal Constitucional, 2005, pp. 9, 21, 28 y 29; Gómez Colomer, Juan Luis, "La instrucción del proceso penal por el Ministerio Fiscal: aspectos estructurales a la luz del derecho comparado", Ciencias Penales, San José de Costa Rica, Revista de la Asociación de Ciencias Penales de Costa Rica, 1997, pp. 36-52. Delmas-Marty, Mireille, Procesos penales de Europa (Alemania, Inglaterra y País de Gales, Bélgica, Francia, Italia, Zaragoza, Edijus, 2000, pp. 518 y 519, 529. Díez-Picazo, Luis María, El poder de acusar. Ministerio Fiscal y constitucionalismo, Barcelona, Ariel Derecho, 2000, pp. 135-139. 
la policía, que realmente será también una nueva relación entre la policía y los ciudadanos. ${ }^{30}$

s) Se quiebra el monopolio de la acción penal por parte del Ministerio Público, en virtud de que la ley determinará los casos en los cuales los particulares podrán ejercer la acción penal ante la autoridad judicial.

t) El Ministerio Público podrá considerar criterios de oportunidad para el ejercicio de la acción penal, de acuerdo con la Ley, con lo cual podrá no comenzar o detener la investigación. Lo anterior puede resultar peligroso, aunque tales decisiones sean impugnables por vía judicial.

u) La Constitución ya establecía el Sistema Nacional de Seguridad Pública. Con la reforma se agregan sus bases mínimas, que más bien son sus facultades y, en algunos casos, sus obligaciones.

v) El principio de que toda pena deberá ser proporcional al delito que sancione y al bien jurídico afectado.

w) No se considerará confiscación la "extinción de dominio" de bienes a favor del Estado, que se ha conocido como bienes asegurados, se precisa que para ellos se establecerá un procedimiento jurisdiccional y autónomo del de la materia penal, que procederá en los casos de delincuencia organizada, delitos contra la salud, secuestro, robo de vehículos y trata de personas, y respecto de los bienes que la Constitución especifica.

Este aspecto es importante porque se golpea al crimen organizado y otros delitos graves en su propio corazón: los inmensos rendimientos económicos que implican y que son la causa de la realización de esos delitos. Como bien dice la exposición de motivos del proyecto, se enfrenta a la delincuencia afectándose directamente a la economía del crimen, se aumentan sus costos y se reducen sus ganancias.

x) Se faculta al Congreso de la Unión para legislar en materia de delincuencia organizada. En consecuencia, las entidades federativas ya no poseerán dicha atribución.

y) El sistema de proceso penal acusatorio y oral entrará en vigor cuando lo establezca la ley, sin exceder el plazo de ocho años, contados a par-

30 García Ramírez, Sergio, "Un cambio con sabor a veneno", cit., nota 26, p. A14. Del mismo autor, “AAgua y veneno? Doble sistema penal”, Examen, México, marzo de 2008, pp. 16 y 17. En este número también resultan interesantes los artículos de Guillermo Zepeda Lecuona, Javier Saldaña y Moisés Moreno. 
tir del día siguiente de la publicación de la reforma en el Diario Oficial de la Federación.

2. Al enunciar los principales aspectos de esta reforma Judicial, en algunos de ellos realicé un pequeño apuntamiento. Considero que los debo completar con una breve reflexión de carácter general, en virtud de que esta reforma va a modificar profundamente la relación del Estado con la sociedad, con la procuración e impartición de justicia, así como con la protección de los derechos humanos. Si llega a tener éxito, es probable que puedan disminuir de modo notable dos de los grandes vicios que están carcomiendo las bases mismas del país: la corrupción y la impunidad. A su vez, la Reforma fracasará si no ataca frontalmente dichos vicios. La principal razón por la que las anteriores reformas no alcanzaron sus objetivos se debió precisamente a que quienes las aplicaron no se enfrentaron a la corrupción y a la impunidad, lo cual no es un problema de la norma, sino de voluntad política, de subordinar los intereses de grupo o particulares a la disposición de la ley, a la aplicación estricta de ésta y no a la simulación de que se hace como que se aplica, a que se quieren resolver los problemas sin enfrentarlos, sólo a base de discursos y de campañas de propaganda en los medios de comunicación.

Expongo algunas reflexiones sobre la "reforma judicial":

a) Ciertamente resulta preocupante que el derecho penal mexicano se va a dividir o van a ser dos, uno ordinario y otro excepcional para combatir el crimen organizado.

El crimen organizado es una realidad actual y además globalizado. Por tal razón, ha entrado en vigor la Convención de las Naciones Unidas contra la Delincuencia Organizada Internacional o Convención de Palermo.

El fenómeno del crimen organizado es característico del siglo XX y del presente, y tiene elementos propios, que generalmente no se conocieron con anterioridad: constituye un desafío al propio Estado, porque en algunos casos es un Estado dentro del propio Estado; tiene un poder corruptor inmenso de las instituciones públicas que abarca desde los niveles más altos de la política, jueces, fiscales, militares y policías hasta los campos empresariales, religiosos y mediáticos; cuenta con personal entrenado con disciplina militar y con armas de alto poder y sofisticadas; tiene una organización internacional extensa; se relaciona y subvenciona, desde grupos terroristas hasta partidos políticos, organizaciones religiosas y no-gubernamentales. 
Así las cosas, tratar de combatirlos con los instrumentos tradicionales del derecho penal es ir al fracaso. Ante los nuevos retos y desafíos es necesario hacerles frente con novedosos instrumentos de carácter legal y con respeto a los derechos humanos. El delito no se combate con el delito.

Ahora bien, hay que admitir que ante el crimen organizado, que no es una asociación delictuosa ni un simple grupo o banda de delincuentes, sí se justifican algunos instrumentos excepcionales para la defensa de la sociedad y de las personas.

Mi preocupación profunda consiste en que esas medidas excepcionales o extraordinarias se vayan a volver ordinarias y que, por razones políticas, por corrupción o por falta de profesionalismo, se apliquen a quien se encuentra muy lejano a algo parecido al crimen organizado.

En esta virtud, la definición constitucional que se aprobó para crimen organizado es muy amplia y en ella caben múltiples supuestos. Hay que precisarla y acotarla. Debe ser una definición de aplicación estricta que no se preste a interpretaciones, más en un país en el cual la regla, con sus excepciones, es la falta de profesionalismo y corrupción de los agentes ministeriales, policiacos y de muchos jueces. El régimen excepcional no puede, por ningún motivo, convertirse en el normal $u$ ordinario.

b) Asimismo, me preocupa la ruptura jerárquica entre el Ministerio Público y la policía de investigación, lo cual va en contra de las tendencias actuales en los países democráticos. Ciertamente, el proyecto dice que las policías, en la investigación de los delitos, actuarán bajo la conducción y mando del ministerio público, pero es el propio artículo constitucional el que les está compartiendo la responsabilidad de la función de investigación. Además, las policías de investigación podrán estar adscritas a órganos distintos del Ministerio Público, incluso secretarías de Estado, y éstos los podrán separar de sus cargos, y si el juez resuelve que dicha separación o cese fue injustificado no podrán ser reinstalados, sólo indemnizados.

En la realidad, se está independizando al policía del Ministerio Público. En caso de órdenes contrarias entre el agente del Ministerio Público y el superior jerárquico en el órgano administrativo, es claro a quién el policía va a obedecer.

Con esta disposición se debilita la procuración de justicia y se aleja al Ministerio Público de que algún día pueda constituirse en un órgano 
constitucional autónomo, debido a ¿qué autonomía va a tener, si la policía de investigación depende administrativamente de una Secretaría de Estado?

c) Se insiste en el Sistema Nacional de Seguridad Pública ¡Qué bueno! En teoría se creó con la reforma constitucional del 31 de diciembre de 1994. A partir de entonces se han gastado cantidades enormes de dinero, pero la inseguridad pública, la criminalidad y el crimen organizado han avanzado en proporciones inimaginables a partir de aquel diciembre de 1994. La conclusión no es difícil de encontrar. Ese Sistema Nacional ha sido y es un fracaso tremendo, lo que lesiona a todos los habitantes de México.

La reforma constitucional se refiere a la selección, ingreso, formación, permanencia, evaluación, reconocimiento y certificación de los integrantes de las instituciones de seguridad pública. ¡Estupendo! No obstante, en 1993 se realizó un gran esfuerzo para crear la carrera de agente del Ministerio Público y de la policía. ${ }^{31}$ Ese esfuerzo rindió frutos en aquel año. Con posterioridad, lo alcanzado se destruyó. Después se volvió a hablar de lo mismo y tan no existen resultados positivos que la reforma judicial insiste en todos estos aspectos. ¿Qué ha ocurrido? Que todo ha sido una farsa, mentiras, declaraciones, discursos, cambio de nombres a las corporaciones, propaganda mediática. Resultados positivos cero. Las escuelas de preparación ministerial y policiaca convertidas en vitrinas de oropel para el lucimiento externo, publicaciones, seminarios y hasta el otorgamiento de "doctorados honoris causa", mientras el crimen organizado se ha apoderado de regiones enteras de México, según el propio decir del presidente de la República.

Las situaciones son diferentes cuando existe voluntad política, seriedad, responsabilidad, profesionalismo y lucha contra la simulación y la corrupción. Expongo un ejemplo: el éxito singular que se ha logrado con el servicio profesional federal de carrera de los defensores de oficio y la labor laudable del Instituto Federal de Defensoría Pública. Claro que sí se puede. Deseo igual éxito a las nuevas intenciones manifestadas en la reforma judicial al Sistema Nacional de Seguridad Pública y sus bases mínimas, que no son nuevas y que no han aportado resultados positivos

31 Carpizo, Jorge, Un año en la procuración de justicia: 1993, México, Porrúa, 1994, pp. 28 у 29, 113-116. 
cuando menos hasta ahora, insisto, por falta de voluntad política. La novedad es que se les otorga rango constitucional.

d) El principio de oportunidad para el ejercicio de la acción penal, que implicará la facultad del Ministerio Público de no iniciar o detener la investigación. La exposición de motivos del proyecto precisa que no será aplicable cuando esté involucrado un interés público importante. Este punto es por demás preocupante, aunque tal vez esa decisión pudiera ser impugnada jurisdiccionalmente. Al respecto nada se dice.

La inquietud consiste en que el criterio de oportunidad pudiese responder a motivos políticos o a la denominada razón de Estado. El Ministerio Público depende del presidente o de los gobernadores, y, como ya expresé, sus agentes pueden ser dados de baja y aun si ganan el respectivo juicio, no tienen el derecho a la reinstalación. Es público el mal funcionamiento del Ministerio Público en el país, con sus muy honrosas excepciones. La mentalidad de los agentes no cambia de la noche a la mañana, menos si no tienen garantía alguna de estabilidad en el cargo.

No desconozco que el criterio de oportunidad presenta, en la teoría, aspectos positivos, como el hecho que no se emplee tiempo en casos muy menores o de poca importancia. No obstante, el Ministerio Público mexicano aún no se encuentra preparado para tal institución. La realidad lo demuestra, y puede ser muy mal utilizada en el contexto de nuestra procuración de justicia.

e) La ruptura del monopolio de la acción penal en manos del Ministerio Público, en principio, es positiva, cuando menos en la teoría. Existe en diversos países.

Se establece en la Constitución que la Ley preverá los casos en los cuales los particulares podrán ejercer la acción penal ante la autoridad jurisdiccional. La exposición de motivos del proyecto se refiere a que ese ejercicio "será evidentemente excepcional, sólo en aquellos casos en los que el interés afectado no sea general", y que dicho ejercicio, como en la cuestión de la coadyuvancia, no implica que el Ministerio Público desatienda el asunto. Esa exposición de motivos continúa diciendo que la finalidad es hacer más transparente la procuración de justicia y propiciar un control ciudadano sobre las funciones de aquélla. ¡Muy bien! Estupendas intenciones.

Empero, guardo algunas inquietudes al respecto, que no pertenecen al ámbito jurídico, sino a nuestra realidad. Por ejemplo, la coadyuvancia en 
la procuración de justicia, teóricamente impecable, degeneró en su aplicación por falta de profesionalismo y respeto a la ley por parte del Ministerio Público, al reconocerse como coadyuvante a quien simultáneamente es juez y parte.

El peligro que encuentro en este aspecto es que, dentro del clima moral que prevalece en México, ${ }^{32}$ los particulares, sin razón jurídica alguna, sino conducidos por fobias, enemistades, razones ideológicas o alguna otra causa, ejerciten la acción penal, con las consecuencias negativas para la justicia que tal conducta acarrearía, y los consecuentes escándalos mediáticos que pueden afectar la honra y el buen nombre de muchas personas.

3. La llamada reforma judicial, entonces, posee virtudes y defectos. Será su aplicación la que la justifique o la repruebe. En México, los problemas actuales de la procuración e impartición de justicia no son, insisto, primordialmente de índole jurídica, sino de falta de voluntad política, desprecio a la ley, corrupción e impunidad. Como jurista no desconozco el valor de la norma, pero es indebido y conduce al fracaso tratar de corregir únicamente a través de la norma situaciones anómalas y vicios que no corresponden al ámbito jurídico.

\section{EL TEMA RÉGIMEN DE ESTADO Y GOBIERNO}

Uno de los seis temas contemplados en la Ley de Reforma del Estado es el de régimen de Estado y gobierno, sobre el cual existen múltiples ideas y propuestas.

Considero que la agenda de este tema podría configurarse con los siguientes rubros:

a) La relección de diputados y senadores con un límite, con el objeto de que, entre otros aspectos, respondan ante sus electores, para que gocen de cierta independencia respecto a las burocracias partidistas y del propio Poder Ejecutivo, y para la preservación de la experiencia.

b) La ratificación de los principales o todos los nombramientos del gabinete presidencial por parte del Senado, para que el presidente pondere mejor las cualidades del candidato y para que exista la posibilidad de impedir un nombramiento notoriamente desacertado.

32 Carpizo, Jorge, "La moral pública en México", Voz y Voto, México, marzo de 2008, núm. 181, pp. 38-45. 
c) En virtud de que un país no puede quedarse sin presupuesto de egresos, si éste no se aprueba en la fecha debida, el que se está aplicando debe prolongar su existencia hasta que se apruebe el nuevo.

El presidente no posee la facultad de veto respecto al presupuesto de egresos de acuerdo con la Constitución, aunque la jurisprudencia contradiga ese texto. Sí podría tener dicha facultad si la naturaleza del presupuesto se modifica. Entonces, dicho proyecto también lo aprobaría el Senado.

d) El presidente debe tener la facultad de presentar al Congreso proyectos de leyes de tramitación prioritaria o urgente. Las cámaras no podrían realizar ninguna modificación al proyecto, pero tendrían la potestad dentro de un número determinado de días de aprobar el proyecto tal y como se envió o de rechazarlo expresamente por mayoría simple. Si transcurridos los términos respectivos, las cámaras no rechazan el proyecto, éste se envía al Ejecutivo para su publicación. Si en un plazo determinado el Ejecutivo no recibe la ley, está autorizado para publicarla.

En un año legislativo, el presidente podría enviar hasta un máximo de 4, 5 o 6 proyectos de tramitación prioritaria y urgente, no más para que no se convierta en el gran legislador.

e) Al párrafo segundo del artículo 108 constitucional, que señala las causas por las cuales el presidente de la República puede ser acusado durante su encargo, agregarle la causal de violación expresa de la Constitución, tal y como estaba contemplada en la Constitución mexicana de 1857.

f) La censura no vinculante a secretarios de Estado por parte del Congreso. En tal situación la renuncia del censurado queda al criterio del presidente. En esta forma existe en varias Constituciones de América Latina.

g) La configuración de un jefe de gabinete, cuyas principales facultades serían la coordinación de aquél y las relaciones con el Congreso. Sería como su nombre lo indica un jefe de gabinete, no un jefe de gobierno.

h) La conversión de las procuradurías de justicia y de las entidades de fiscalización en órganos constitucionales autónomos.

i) La introducción para casos precisos y con requisitos calificados de las figuras de la iniciativa popular y del referendo. 
Ahora bien, no es posible realizar reformas a los poderes Ejecutivo y Legislativo federales, y descuidar al Judicial. En consecuencia, considero que se debe ponderar:

j) La creación de un Tribunal Superior de Justicia de la Federación para garantizar la unidad de la interpretación de las leyes, resolviendo las contradicciones de tesis de los múltiples tribunales colegiados de circuito. Además, entre sus otras facultades se encontraría la resolución de conflictos de competencia entre tribunales.

k) Hay que suprimir cualquier intervención de la Suprema Corte o del probable Tribunal Superior de Justicia de la Federación respecto al Consejo de la Judicatura Federal para que éste goce de autonomía técnica y funcional.

Ninguno de los órganos mencionados debe revisar los actos del Consejo de la Judicatura, en razón de que su labor esencial es jurisdiccional y no la administración de la carrera judicial.

l) Se debe modificar el procedimiento de los nombramientos de los ministros de la Suprema Corte de Justicia de la Nación. El actual sistema ha mostrado deficiencias y carencias.

ll) Revisión y, en su caso, aprobación de la iniciativa de la Ley de Amparo que se encuentra en el Congreso de la Unión. Es una buena iniciativa, aunque perfectible, que modernizaría, agilizaría y suprimiría formalismos innecesarios a nuestro juicio de amparo.

m) Las sentencias de amparo que declaren inconstitucional una ley cuando hayan integrado jurisprudencia, deben tener efectos erga omnes. La fórmula Otero, en consecuencia, debe desaparecer, en virtud de que vulnera el principio de supremacía constitucional, niega el valor normativo de la Constitución y su carácter protector de los derechos y libertades de los individuos, rompe la norma de igualdad, y lesiona el principio de economía procesal. ${ }^{33}$

$*$

33 Carpizo, Jorge, Concepto de democracia y sistema de gobierno en América Latina, cit., nota 17, pp. 137-167; Valadés, Diego, El gobierno de gabinete, 2a. ed., México, UNAM, Instituto de Investigaciones Jurídicas, 2005, pp. 36-68; del mismo autor, La parlamentarización de los sistemas presidenciales, México, El Colegio Nacional-UNAM, Instituto de Investigaciones Jurídicas, 2007, pp. 35-45, 65-87. 
La Constitución mexicana de 1917, como cualquier otra, necesariamente continuará adecuándose a una sociedad cambiante y cada vez más plural. La norma habrá de reconocer nuevos retos del sistema democrático, a la vez que amplía las libertades y derechos de los habitantes. En el contexto actual del país, es probable que la interpretación constitucional de última instancia continúe fortaleciéndose, lo cual es adecuado y deseable. No obstante, la tradición de la reforma constitucional difícilmente podrá ser obviada en el corto plazo.

La experiencia de estas últimas décadas, de diálogo, negociación, concertación y reformas, habrá de imperar para que las modificaciones al marco constitucional continúen realizándose en paz y a través de los procedimientos que la propia Constitución señala para su actualización y renovación.

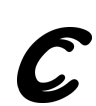

